Gerión. Revista de Historia Antigua

ISSN: 0213-0181

http://dx.doi.org/10.5209/GERI.56965

\title{
Los tituli vasis fictilibus inscripti del CIL IV. Informatización y análisis cuantitativo de sus objetos epigráficos
}

\author{
Daniel Jesús Martín-Arroyo Sánchez ${ }^{1}$; José Remesal Rodríguez ${ }^{2}$
}

Recibido: 20 de julio de 2016 / Aceptado: 16 de mayo de 2017

Resumen. La informatización de la epigrafía anfórica contenida en el volumen IV del Corpus Inscriptionum Latinarum resulta altamente significativa para los estudios económicos del mundo romano. El valor dado a sus características cuantitativas y cualitativas se ha puesto en evidencia por contraposición a los tituli picti anfóricos publicados en otras obras. Se detallan en el presente trabajo la distribución de los tituli vasis fictilibus inscripti en el CIL IV, parte de la bibliografía que apoya su estudio y las estrategias seguidas para su organización e interpretación. Se ha sintetizado una documentación notablemente fragmentada, publicada en varios suplementos y por distintos autores a lo largo de un siglo. Su análisis posterior muestra la composición temática de los tituli picti y la clasificación tipológica de sus soportes epigráficos según los autores del CIL IV.

Palabras clave: Pompeya; ánfora; Epigrafía; Historiografía; cuantificación.

\section{[en] The Tituli Vasis Fictilibus Inscripti from CIL IV. Computerization and Quantitative Analysis of their Epigraphic Objects}

\begin{abstract}
The computerization of amphoric epigraphy from volume IV of Corpus Inscriptionum Latinarum is very significant for the economic studies of the Roman world. The value of their quantitative and qualitative characteristics has been obtained by their contraposition with tituli picti published in other works. This work shows the distribution of the tituli vasis fictilibus inscripti from CIL IV, the related bibliography that supports their study, and the strategies followed for its organization and interpretation. The documentation was very fragmented, published in multiple supplements by different authors over a century, and was in need of a summarization. The subsequent analysis of this summarized documentation shows the thematic composition of the tituli picti and the typological classification of their epigraphic carriers according to the authors of $C I L$ IV.
\end{abstract}

Keywords: Pompeii; Amphora; Epigraphy; Historiography; Quantification.

Sumario. 1. Introducción. 1.1. Contexto CEIPAC/EPNet del vaciado. 1.2. Objetivos del vaciado. 1.3. Criterios de vaciado. 2. Distribución de los tituli picti en el CIL IV. 3. Cuantificación de los objetos epigráficos según la tipología del CIL IV. 4. Conclusiones. 5. Referencias bibliográficas.

Cómo citar: Martín-Arroyo Sánchez, D. J. - Remesal Rodríguez, J. (2017) Los tituli vasis fictilibus inscripti del CIL IV. Informatización y análisis cuantitativo de sus objetos epigráficos, en Gerión 35/1, 255-275.

\footnotetext{
$1 \quad$ Universidad de Barcelona

E-mail: martin-arroyo@ub.edu

2 Universidad de Barcelona

E-mail: remesal@ub.edu
} 


\section{Introducción}

\subsection{Contexto CEIPAC/ EPNet del vaciado}

El presente estudio trata los tituli vasis fictilibus inscripti recopilados en el volumen IV y los correspondientes supplementa del Corpus Inscriptionum Latinarum (CIL). En ellos se recogen las inscripciones provenientes de los yacimientos de Pompeya, Estabia, Herculano y su entorno. Esta actividad se ha desarrollado como parte de la labor del CEIPAC en el seno del Proyecto EPNet. El grupo de investigación CEI$\mathrm{PAC}^{3}$ se dedica al estudio de la epigrafía anfórica desde 1989. Ha proyectado su investigación internacionalmente, destacando sus excavaciones del Monte Testaccio. La documentación así generada se va integrando paulatinamente en su base de datos CEIPAC, además de todos aquellos datos procedentes de las publicaciones en esta materia. El trabajo continuado del equipo de investigación y sus colaboradores desde 1995 ha acumulado un volumen ingente de información que conlleva sus propios retos y posibilidades. ${ }^{4}$ En este punto la subvención del Proyecto EPNet ${ }^{5}$ ha permitido la constitución de un equipo multidisciplinar dedicado a la implementación de la base de datos y la interpretación histórica de sus contenidos mediante nuevas herramientas metodológicas. ${ }^{6}$

En el estado actual de la investigación, la información relativa a los tituli picti ${ }^{7}$ del CIL IV se ha recogido en un documento Excel.$^{8}$ Este soporte se utilizará para el análisis de dicha información. El presente trabajo muestra los primeros resultados de una investigación que avanzará paulatinamente sobre diversos aspectos de los datos recopilados. Cuando concluya el proceso de análisis y se publiquen todos sus resultados, los registros ${ }^{9}$ se integrarán en la base de datos CEIPAC. Así, toda la información será accesible a través de Internet para la comunidad científica.

\subsection{Objetivos del vaciado}

Este trabajo se enmarca, por tanto, entre las líneas de investigación del CEIPAC y EPNet. Su prosecución buscará a largo plazo un mejor conocimiento de la producción y el comercio de alimentos en el mundo romano. Para ello aborda con particular interés el análisis de la epigrafía relativa a los recipientes en los que se comercializaban dichos alimentos. En concreto, el vaciado del CIL IV atiende a las inscripciones relacionables con el comercio de los derivados de la uva y el pescado, buscando un

Centro para el Estudio de la Interdependencia Provincial en la Antigüedad Clásica (http://ceipac.ub.edu).

4 Remesal Rodríguez 2007; ID. 2008; ID. 2012; ID. 2013; AquiluÉ 2014, 45-46; Remesal RodríGuez et alii 2015.

5 FP7/2007-2013/ERC grant agreement $\mathrm{n}^{\circ}$ 340828. http://www.roman-ep.nethttp://www.roman-ep.net. El CEIPAC también es beneficiario del proyecto HAR2015-66771-P (MINECO/FEDER, UE).

6 Remesal Rodríguez et alii 2014; Remesal Rodríguez et alii 2015.

7 En este trabajo se entiende la expresión "titulus pictus" como inscripción realizada con tinta, pintura o carboncillo sobre un objeto.

El concepto "objeto" u "objeto epigráfico" se toma de la terminología empleada en la base de datos CEIPAC. Se trata aquí del soporte físico de una inscripción, una pieza del instrumentum domesticum en general, especialmente en alusión a las ánforas.

8 Los protocolos y herramientas de vaciado propios del CEIPAC han sido descritos en: AyLlón MARTín - PÉREZ GoNZÁLEZ 2013; PÉREZ GoNZÁLEZ 2014.

9 En este trabajo se entiende el término "registro" como unidad de información o tipo de dato que se puede diferenciar dentro de un documento (incluidos los epigráficos) o base de datos. 
mejor conocimiento del mismo. Dichos productos serían los más abundantes con diferencia dentro de la amplia gama de alimentos envasados que no estaban directamente afectados por el servicio annonario, al menos no en la misma medida que el trigo y el aceite. Expresado de otra forma, serían productos que dependerían en mayor grado de la actividad privada de los comerciantes romanos.

La documentación epigráfica a estudiar se diferencia esencialmente de la perteneciente a las ánforas olearias Dressel 20. Las inscripciones sobre este tipo anfórico se caracterizan por una mayor regularidad formal y una gran cantidad de registros, multiplicándose los epígrafes que aparecen sobre cada objeto por un destacado número de hallazgos. Además, la Dressel 20 cuenta con la ventaja de tener una zona de origen limitada al valle del Guadalquivir y puntos clave de distribución annonaria en Roma y el Limes. Estas características sitúan a las Dressel 20 en una posición destacada de la investigación, que tiene su reflejo en la base de datos CEIPAC. Así, sobre la cifra de 38780 objetos epigráficos extraída de dicho catálogo, 22766 corresponden al tipo Dressel 20. Es decir, el 58,7\% de los objetos. El peso de la epigrafía sobre Dressel 20 es igualmente destacable si se atiende a los tituli picti. De un total de 4869 objetos que contienen tituli, 3649 son Dressel 20 (Fig. 1) y 3323 de ellos provienen del Monte Testaccio. El resto de tipos cerámicos que portan tituli ofrecen un total de 1220 objetos, procediendo 306 de ellos del Testaccio. De estos se pueden excluir otros contenedores de aceite:

- 185 corresponden a las ánforas olearias Tripolitanas, perteneciendo todas al Testaccio.

- 11 son Africanas, perteneciendo 8 al Testaccio.

Además, es previsible un aumento considerable de este tipo de registros conforme se publiquen y vacíen en la base de datos los nuevos volúmenes de la colección Instrumenta dedicados a las excavaciones del Testaccio. Las Tejarillo 1 recopiladas en la base de datos no contienen tituli picti. Las ánforas olearias orientales, por su variedad y escasa representatividad, no serán tenidas en cuenta para este cómputo.

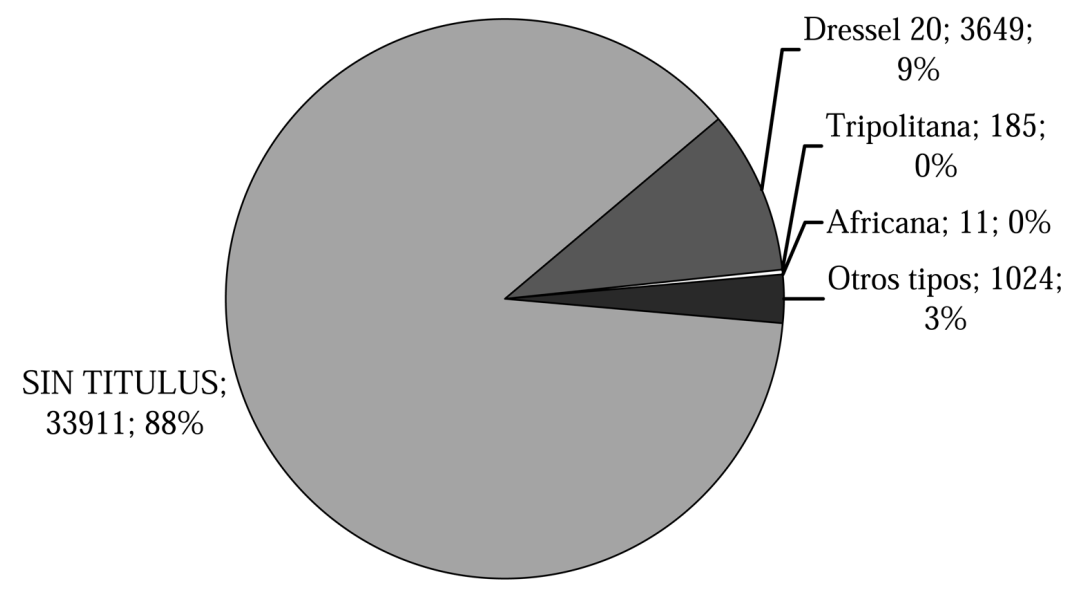

Figura 1. Representatividad de los tituli picti sobre 38.780 objetos de la base de datos CEIPAC. 
De tal forma, la práctica totalidad de las ánforas no olearias que contienen tituli se reducen a un total de 1024, proveniendo 113 del Testaccio.

Con todo ello se quiere destacar el valor cuantitativo del vaciado del CIL IV para la base de datos CEIPAC, que aportará 2576 objetos con tituli picti. Esta nueva información resulta especialmente significativa en relación al volumen de tituli picti no olearios que está disponible hasta el momento en dicha base de datos. Es decir, se incrementará notablemente el número de inscripciones útiles para el estudio de los derivados de la uva y el pescado, entre otros menos frecuentes. Esta relación proporcional entre los tituli preexistentes y aquellos nuevos que se incorporarán a la base de datos CEIPAC aparece representada en la Figura 2. Los tituli picti olearios del CIL supondrán un añadido de 243 objetos (del tipo anfórico PO11) a los 3845 (Dressel 20, Tripolitana y Africana) ya existentes en la base de datos CEIPAC. Los contenedores no olearios del CIL IV ascienden a un total de 2326, que se añadirían a los 1024 de la base de datos CEIPAC. Así, su volumen representaría más de un 69\% en el total de los futuros registros de este tipo.

Cabe añadir algunas precisiones sobre la forma en que se han realizado los cálculos referidos. El tipo anfórico Pompeii 11 (PO11) se representa en la correspondiente tabla de formas del CIL IV a partir del soporte del titulus 4627. Este prototipo se corresponde con las ánforas olearias clasificadas como Tripolitana 1. Las PO11 del CIL supondrían el $56 \%$ de las ánforas Tripolitana 1 al incorporarse a la base de datos CEIPAC. Por otro lado, las Dressel 20 están escasamente representadas en Pompeya. Por ello no se ha restado su número del total de las ánforas no olearias del CIL IV. Las Dressel 20 pompeyanas estarían incluidas en un reducido porcentaje de los ejemplares clasificados como PO10 y PO29. ${ }^{10}$ En efecto, la clasificación tipológica de los objetos documentados por los autores del CIL IV plantea dudas. Estos auto-

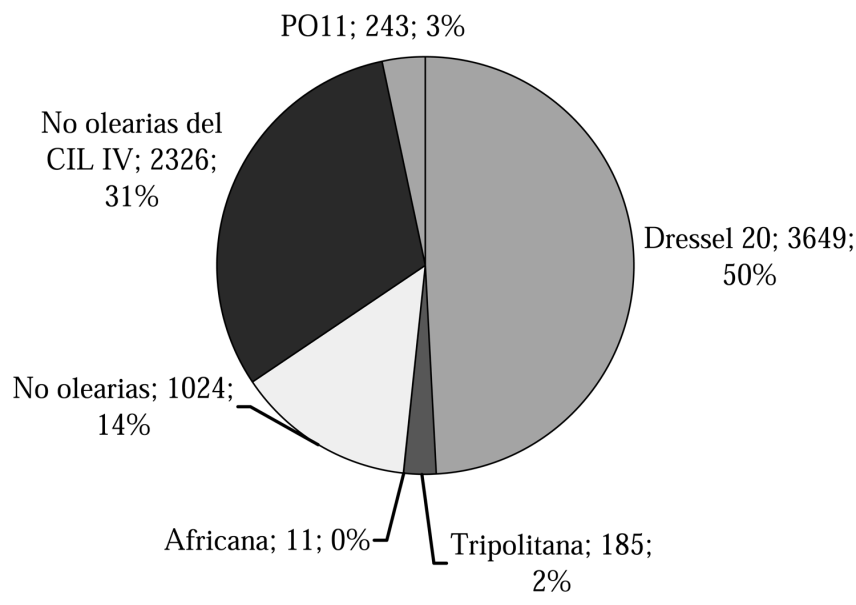

Figura 2. Representatividad de los objetos con tituli picti de la base de datos CEIPAC con referencia al vaciado del CIL IV.

10 ManaCORDA 1977, 131. 
res dispusieron de unas tablas tipológicas muy limitadas en cuanto al número y la morfología de las formas representadas. Así pues, distintos tipos reconocibles por la investigación actual se recogieron eventualmente bajo una misma forma Pompeii (PO). Por tanto, aunque se establezcan equivalencias actualizadas, las referencias a los objetos del CIL IV se continuarán citando bajo la clasificación Pompeii (PO) en este trabajo.

Otro objetivo a largo plazo de la investigación que encabeza esta publicación es promover un mayor conocimiento de la estructura de los tituli picti. En este sentido el sistema de las Dressel 20 no será objeto prioritario de análisis, pero sí se pondrá cierta atención sobre las PO11. Así pues, aun tratándose de ánforas olearias, sus tituli picti son menos conocidos. Los tituli de las ánforas de salazón en particular cuentan con diversas propuestas interpretativas. Unas han optado por sistemas de clasificación análogos al de las Dressel 20, utilizando letras griegas en la denominación de los diferentes registros que componen los tituli. La distribución de S. Martin-Kilcher ofrece, sin embargo una codificación a partir de letras latinas y cifras arábigas. Esta es más adecuada para su inclusión en la base de datos CEIPAC, pues evita la confusión con el sistema creado por H. Dressel para su forma $20 .{ }^{11}$ Esto no impide que en un futuro el significado de ciertos registros de ambos sistemas se pueda equiparar. No obstante, la investigación debería avanzar primeramente en la validación de las clasificaciones actuales para los tituli no pertenecientes a las Dressel 20. Por otro lado, si fuera necesario, también se podrían completar o matizar tales distribuciones o proponer otras alternativas.

Esta labor se integra en la vertiente metodológica y plan de trabajo del Proyecto EPNet. Así pues, busca la definición de un esquema para la estructuración de parte del registro anfórico. Además, procura la implementación del sistema informático de la base de datos CEIPAC y aumenta el volumen de información contenida. Estos resultados se obtienen mediante la práctica del vaciado y el planteamiento de búsquedas específicas para la nueva interfaz usuaria que generará el Proyecto para la base de datos. La definición semántica resultante también afectará a la interconexión con otras bases de datos, conforme plantea EAGLE/Europeana. ${ }^{12}$ Otros aspectos a cubrir son la difusión periódica de los resultados del Proyecto y la creación de directrices y protocolos. Así pues, en este trabajo se avanzan condicionantes y principios de actuación de las primeras fases de la investigación, buscando una mejor definición de los mismos y su renovación en el debate académico. El interés se centra en el análisis de la documentación utilizada, los registros del CIL IV. Se establecen así las bases para una argumentación y revisión crítica de los futuros resultados de la investigación.

Volviendo sobre los límites del trabajo en curso, se han cuantificado los objetos, pues ofrecen una información más cerrada. Es decir, están sujetos a un menor número de interrogantes e interpretaciones. La cifra de 2576 vasos contenidos en el CIL IV es estable, mientras que la cantidad de tituli dependerá de la clasificación y consecuente distribución por entradas que se haga con ellos. Otro aspecto metodológico aquí manifiesto es la concentración bibliográfica sobre el CIL IV. Una parte de sus tituli provienen a su vez de vaciados bibliográficos, siendo las obras de referencia

Aguilera Martín 2004, 120-122.

12 www.eagle-network.eu/about/who-we-are. AQUILUÉ 2014, 44. Un estado de la cuestión sobre los recursos digitales para la Epigrafía en ELLIOTT 2015. 
de difícil acceso en la actualidad. Su estudio resultaría de interés para comprender la génesis del CIL IV, aunque no está entre los objetivos considerados por el momento. Una fase ulterior tendría en cuenta la incorporación de grafitos y sellos al análisis de la epigrafía cerámica del entorno pompeyano. Los grafitos ocupan sus respectivos apartados entre los tituli. Los sellos aparecen mencionados ocasionalmente, cuando están vinculados a un titulus. Esta fase del vaciado ha permitido la recopilación de 18 ejemplares. Un elenco más exhaustivo de los mismos aparece en el CIL X. En este volumen cada tipo del instrumentum domesticum tiene una sola entrada al catálogo general y los ejemplares se numeran consecutivamente dentro de cada grupo. A continuación se expone un breve listado que selecciona los apartados temáticos de interés, tanto por los soportes cerámicos como para la investigación de los sistemas de sellado (7) y pesado de los contenidos (8):

1. Dolia Pompeiana: 8047, 1-23.

2. Pelves fictiles (mortaria quae dicuntur) Pompeianae Herculanenses Stabianae: $8048,1-51$.

3. Amphorae Pompeianae: 8049, 1-16.

4. Lucernae Herculanenses et Pompeianae: 8052, 1-30.

5. Vasa et vascula reperta Pompeiis Herculaneive: 8055, 1-6.

6. Vascula et reliqua cretacea praeter Pompeiana: 8056, 1-634.

7. Signacula Pompeiana et Herculanensis: 8058, 1-97.

8. Staterae, pondera, mensurae reperta Herculanei et Pompeiis: 8067, 1-93.

También existen obras que han abordado con posterioridad la epigrafía anfórica del ámbito pompeyano, escogiendo una parte para su interpretación. J. Andreau lo hizo en un marco de estudio socio-profesional que considera a los productores de vino, los "mercaderes" y los tenderos, además de los productores de garum. ${ }^{13}$ Este trabajo sitúa las lecturas de los tituli en relación a la onomástica pompeyana, especialmente la proveniente de las tabulae ceratae que componían el archivo privado de L. Caecilius Iucundus. Al igual que en tal estudio precursor, prosopografía y análisis económico son dos vías de actuación complementarias que se emplearán en la investigación de los tituli del CIL IV. Una de las limitaciones que encontró J. Andreau fue la falta de información sobre los soportes anfóricos. En este campo se realizaron ciertos avances en años posteriores por D. Manacorda y C. Panella. Estos investigadores revisaron una parte considerable de las ánforas pompeyanas, asociándolas a las inscripciones del CIL IV cuando los restos conservados lo permitían. También las identificaron según las tipologías convencionales, fotografiaron y dibujaron un buen número de ejemplares y crearon subgrupos, particularmente en el caso de las PO12 o Dressel 2-4. ${ }^{14}$

C. Giordano y A. Casale han publicado un catálogo de inscripciones pompeyanas inéditas, descubiertas entre 1954 y 1978; esta recopilación incluye 128 inscripciones sobre ánforas, empleando las referencias tipológicas propias del CIL IV para los soportes y las tintas; en ella también resulta de interés la publicación de los calcos de buena parte de estas inscripciones. ${ }^{15} \mathrm{~A}$. Marangou-Lerat se centró en el estudio de las ánforas cretenses; en su obra se abordan los testimonios literarios relativos al vino y la viña en Creta desde el siglo VI a.C. hasta el VI d.C., los talleres productores, la

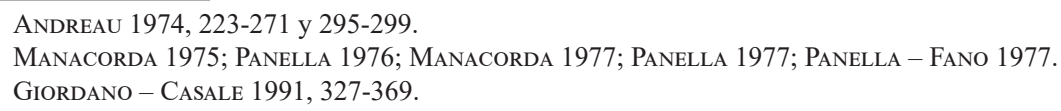


tipología y la epigrafía, tanto sellos como tituli. Entre los tituli ocupan una posición destacada los de Pompeya y su entorno. ${ }^{16} \mathrm{~J}$. T. Peña parte de la agrupación de textos epigráficos, limitando con ello también la tipología de las ánforas en cuestión; una vez efectuadas las pertinentes precisiones formales a la clasificación de las ánforas, deduce nuevas lecturas para los contenidos de las mismas. ${ }^{17}$ Desde el punto de vista de las salsas de pescado, los tituli sobre urcei PO06 han sido objeto preferente de análisis, aunque también se han documentado recientemente algunos pertenecientes a la forma PO04 o Dressel 21-22. ${ }^{18}$ Por último, otros artículos, que no tratan específicamente la cuestión epigráfica, resultan útiles en tanto que exponen la naturaleza y evolución del comercio de cerámica relativo a Pompeya. ${ }^{19}$

Las lecturas de la bibliografía comentada serán integradas en la base de datos CEIPAC según se considere conveniente, tras una posterior revisión de las mismas. No obstante, el CIL IV es la recopilación por excelencia sobre la que fundamentar la toma de datos inicial. Además de su sistematicidad y volumen, recoge una gran cantidad de información irrecuperable, pues muchos tituli se han deteriorado o han desaparecido. Al margen de que una parte de este patrimonio pueda ser reidentificado con nuevas técnicas infográficas, ${ }^{20}$ el CIL IV se constituye como fuente primordial a día de hoy. Por otro lado, los avances en el conocimiento de la epigrafía anfórica y las nuevas técnicas de análisis sugieren la necesidad de informatizar su estudio. Se superará con ello la limitación del formato impreso, permitiendo seleccionar, agrupar y visualizar la información de manera alternativa. Además, los tituli picti que se tratan en el presente trabajo constituyen un conjunto documental significativo en el compendio particular de la epigrafía anfórica y en general para las fuentes correspondientes a los estudios económicos del mundo romano.

\subsection{Criterios del vaciado}

El vaciado epigráfico se ha organizado con vistas a un plan de trabajo que propone la consecución paulatina de los objetivos descritos. Es decir, se trata de un "vaciado crítico" que busca un equilibrio entre la conservación de la información objetiva y la interpretación de la misma. Téngase en cuenta que la noción de objetividad ya viene coartada por la intervención de los autores del CIL IV y, en algunos casos, de sus propias fuentes historiográficas. Ni siquiera cuando se incluyen dibujos o calcos de los tituli se puede hablar en términos absolutos, pues los registros quedan sometidos a las técnicas de reproducción y a la interpretación de sus artífices. Esta deriva de la información debe tenerse en cuenta a la hora de analizar los datos y valorar la verosimilitud de los resultados. Con todo ello los criterios seguidos por el vaciado en cuestión se pueden agrupar en tres bloques:

1. Selección de un caso de estudio.

2. Adecuación a las estructuras y criterios de vaciado preestablecidos.

3. Inclusión y articulación de la información útil para futuras consultas.

\footnotetext{
MARANGOU-Lerat 1995.

PEÑA 2007b.

18 Incluyendo referencias a la bibliografía anterior sobre la forma PO06, CAPELLETO et alii 2013. Sobre las PO04, BERNAL et alii 2014.

19 De Sena - IKäheimo 2003; PeÑa - McCallum 2009a; PeÑa - McCallum 2009b.

20 CORMACK et alii 2007.
} 
La selección de caso de estudio daría lugar a lo que podría denominarse "vaciado dirigido", enfocado hacia la resolución de problemáticas históricas en cierta medida acotadas. A las anteriores argumentaciones sobre la idoneidad del CIL IV para esta labor se deben añadir otras consideraciones vinculadas a los objetivos generales de la investigación. En primer lugar estaría la variedad funcional y tipológica de los recipientes. En segundo lugar, la limitación espacial y cronológica del contexto arqueológico. Con esto último se alude al entorno afectado por la erupción del Vesubio; este cataclismo marca a su vez una datación ante quem (79 d.C.) para los objetos y tituli. El límite cronológico inicial dependerá de los casos particulares y su valoración, teniendo en cuenta cuestiones como el carácter residual o la reutilización de los recipientes, a veces recuperados fragmentariamente. ${ }^{21}$ Un elemento orientativo al respecto son las dataciones consulares, que podrían indicar la ocasional preservación de los tituli sobre vasos conservados o reempleados durante considerables lapsos temporales. En cualquier caso esta limitación espacio-temporal destaca frente a la habitual laxitud de los contextos arqueológicos. El conjunto de estas características ofrece evidentes ventajas para la identificación de patrones en la estructura de los tituli y en su relación con el comercio.

El empleo de las herramientas y procedimientos preestablecidos para el vaciado ${ }^{22}$ procura la correcta integración de la información en la base de datos CEIPAC. De tal forma, futuras búsquedas ofrecerán unos resultados tan coherentes como la información bibliográfica de partida haya sido capaz de proporcionar. No obstante, existen particularidades en la documentación que no tienen cabida actualmente en la estructura de la base de manera optimizada para su gestión. Por ejemplo, en relación a la fecha y al lugar de hallazgo específico, no se concretan por registros separados los distintos componentes. Aunque esta carencia se puede suplir parcialmente ideando estrategias de búsqueda, supone un trabajo añadido que no siempre puede garantizar unos resultados óptimos.

Los casos de Pompeya y Herculano ofrecen particularmente un registro por habitaciones o viviendas. Así pues, la ciudad se divide en regiones, insulae y domus (también aedificia o aedes), llegando a especificarse la pieza en concreto del edificio (caupona, atrium, viridarium...). Sistematizar esta información conlleva dificultades, tales como la utilización de numeraciones diferentes en el parcelario urbano o la edición incompleta del Corpus Topographicum Pompeianum. Sin embargo, existen en la actualidad herramientas y foros capaces de suplir estas carencias. Se trata concretamente de los sistemas de información geográfica (SIG) y del navegador desarrollado por el Pompeii Bibliography and Mapping Project. ${ }^{23}$ En definitiva, hay aspectos específicos de esta investigación, como pudiera suceder con cualquier otra, que no se ven satisfechos por la estructuración de la base de datos CEIPAC. Esta condición, impuesta por los propios objetivos globalizantes de la base, puede superarse con estrategias complementarias. La implementación tecnológica y los acuerdos de interconexión podrían configurar buena parte de estas futuras vías de actuación.

Se ha visto hasta ahora cómo los contenidos del CIL IV se adaptan en mayor o menor medida a las estructuras de vaciado. Los objetivos propios de esta investi-

21 Para una visión completa de las múltiples eventualidades que conforman el registro arqueológico cerámico, con abundantes ejemplos procedentes de Pompeya y Herculano, véase PEÑa 2007a.

22 Ayllón Martín - PÉrez González 2013; Pérez González 2014.

$23 \mathrm{http} / / /$ digitalhumanities.umass.edu/pbmp. 
gación ofrecen otra perspectiva en cuanto a selección de la información útil y articulación de futuras consultas. En este sentido, a diferencia de los objetos, los tituli ofrecen una complejidad mayor que será debidamente atendida más adelante. En este trabajo sólo cabe apuntar que esto conllevará nuevas fórmulas y campos de registro de la información. En el primer caso, el campo "Tinta" podrá ser rellenado con la entrada "NIG" (nigrum), constatada en el CIL frecuentemente como "nero" o "colore nigro". Hasta ahora este campo había de cumplimentarse como "INC" (incertum), cubriendo un arco variable de los códigos dispuestos a tal efecto. La entrada "NIG" añadirá precisión al registro, respetando la ambigüedad de lo constatado en el CIL como fuente fundamental. Así pues la variabilidad se verá restringida a la disociación entre atramentum (ATR) y carbone (CAR), únicas fórmulas que hasta la fecha definen una "tinta" de color negro. Otro condicionante del vaciado proviene de la grafía empleada en el $C I L$ IV, pues sus editores emplearon cuños modificados para representar variaciones formales o estados de conservación. ${ }^{24} \mathrm{Al}$ respecto destaca para esta investigación la incorporación al vaciado de los tituli en alfabeto griego. Si bien esta y otras particularidades pueden solventarse de diverso modo, como se ha propuesto para la "Tinta", queda el reto de la estructuración formal de los contenidos. Tal perspectiva ha sido ya afrontada para los registros delta de las ánforas Dressel 20 bajo la noción de "codex". ${ }^{25}$ La conceptualización a este nivel interno también cuenta con ciertos precedentes para los tituli pertenecientes a otros tipos anfóricos. ${ }^{26}$ La reinterpretación crítica de los tituli picti del CIL IV habrá de tener en cuenta estos precedentes metodológicos para dar respuesta a los objetivos planteados por la investigación. Sin embargo, la fidelidad debida a la transmisión de la información del CIL IV y, al mismo tiempo, su lectura crítica como construcción historiográfica, promueven un tratamiento secuencial. Así, completada una primera fase del vaciado, se analiza a continuación aquella información estructurada de una forma más definitiva, la relativa a los objetos epigráficos. No obstante, esta parte del trabajo espera ofrecer nuevos criterios para la interpretación subsiguiente de los tituli picti.

\section{Distribución de los tituli picti en el CIL IV}

La redacción de un catálogo puede prolongarse en el tiempo y en ella pueden intervenir diversas personas. Este es el caso del CIL IV. En este proceso, pese a que existan unas convenciones más o menos homogéneas, la documentación de base puede aparecer mermada en un aspecto u otro. Además, la concepción de la información relevante cambia en cada momento, según se plantee o avance la investigación. Con la voluntad de aclarar este proceso se ha dispuesto la siguiente síntesis. En ella se explica la composición de este volumen IV y la situación de los tituli picti en el mismo.

Las diversas ediciones que componen el CIL IV se han sucedido entre 1871 y 2011. Al tomo original se fueron añadiendo supplementa, divididos en cuatro partes compuestas a su vez por uno o varios tomos. La Berlin-Branderburgische Akademie der Wissenschaften pone a disposición del usuario de su página web una completa

\footnotetext{
24 Los criterios de transcripción utilizados para el CIL XV son comparables y ejemplifican la diversidad de casos hallados en el CIL IV. Véase una síntesis de los primeros en Aguilera Martín 2004, 125.

25 Aguilera Martín 2004, 113 y 123-124.

26 Entre los más recientes: Martínez Maganto 2000; Lagóstena Barrios 2002-2003.
} 
información sobre los componentes del volumen IV, además de las versiones PDF del volumen original y las supplementi partes $I$ y $I I .{ }^{27}$ Esta relación da cuenta de la fragmentación del material editado al que se ha tenido acceso para la redacción de este trabajo. A ello hay que añadir la distribución de los archivos en formato PDF que se han empleado. Estos han facilitado la impresión de la parte correspondiente a los Tituli vasis fictilibus inscripti. Así, el papel ha sido también soporte necesario para el proceso de vaciado. Sobre estos documentos se fueron anotando los números de inventario provisionales y otros apuntes, conforme se transcribía en formato Excel la información de cada entrada del CIL. Para agilizar el proceso se han completado las columnas del Excel relativas a un mismo tipo de información escogiendo grupos de entradas. Estos grupos responden generalmente a la paginación de la edición impresa, con diversas concesiones a la agrupación temática del CIL o a la complejidad de las inscripciones que se iban transcribiendo. La edición impresa, sus copias digitalizadas en PDF y las impresiones en papel de estas últimas han sido utilizadas conjuntamente para el vaciado epigráfico, el cotejo de notas a las entradas del CIL y la contextualización literaria del material estudiado.

A continuación se exponen los datos relativos a la distribución de los tituli en el CIL IV (Fig. 3). Se ha distinguido entre editores del volumen original y las Supplementi partes y los autores de los capítulos Tituli vasis fictilibus inscripti. Notas y tablas tipológicas (Vasorum formae) se indican junto a las páginas en que aparecen. La tabla I se recoge una vez más junto a las generadas para la edición de 1909, al final de dicha obra. Sólo la edición de 1871 contiene los dibujos de los tituli separados de sus respectivas entradas al catálogo, compilándose en las tablas indicadas al final del tomo. Los saltos en la numeración de páginas y entradas de catálogo se producen por la exclusión de los grafitos. En efecto, la epigrafía Graphio scripta se incluyó en estos apartados Tituli vasis fictilibus inscripti. No obstante, los grafitos se diferenciarían de los tituli picti por la técnica empleada y por su utilidad o interpretación. Así pues, los grafitos podrían vincularse a los alfareros o a los propietarios de los vasos. Por otro lado, los tituli estarían más relacionados con el comercio de los productos envasados.

El cómputo de las entradas al catálogo diverge del correspondiente a los objetos o soportes epigráficos. Estas diferencias derivan de duplicaciones en las entradas al catálogo, tales como CIL IV 10391 y 10391a. Estas pueden corresponder a la inclusión de inscripciones cuando el catálogo ya contaba con una numeración de sus entradas, ordenadas por temática. De tal forma se evitaría el cambio de la numeración subsiguiente. Una situación diferente es la ofrecida por aquellas entradas del CIL IV que recogen una misma inscripción que se repite sobre varios objetos. La asignación de referencias diferenciadas en el Excel de vaciado ha requerido la asignación de letras a los números de entrada al catálogo CIL IV. A diferencia de las anteriores, estas letras se disponen alfabéticamente desde el primero hasta el último de los números idénticos. Por ejemplo, $C I L+\mathrm{IV}+9675$ a y $C I L+\mathrm{IV}+9675$ b. Otras formas de catalogación explican las diferencias de cómputo entre las entradas del CIL IV y los objetos resultantes del vaciado (Fig. 3). Los siguientes ejemplos exponen tal diversidad de criterios de catalogación:

27 http://cil.bbaw.de/dateien/cil_baende.html\#oben. 


\begin{tabular}{|c|c|c|c|c|c|c|}
\hline 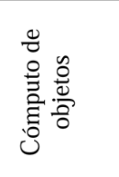 & 芯 & 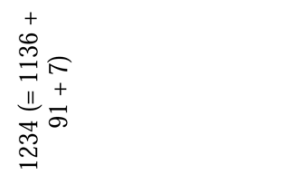 & : & $\underset{\sim}{\mathscr{O}}$ & $\stackrel{\stackrel{N}{N}}{ }$ & 唸 \\
\hline 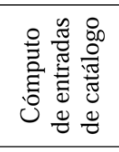 & $\underset{\mathcal{N}}{\tilde{N}}$ & $\stackrel{\tilde{\omega}}{\leftrightarrows}$ & $\stackrel{\llcorner}{\leftrightarrow}$ & $\overline{\mathrm{\sim}}$ & $\cong$ & 売 \\
\hline 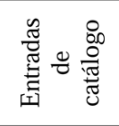 & 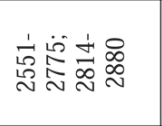 & 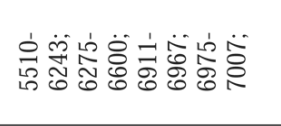 & mîे & 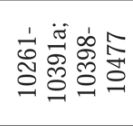 & 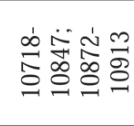 & \\
\hline 莺 & 崖公 & & & & & \\
\hline 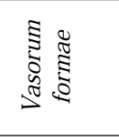 & 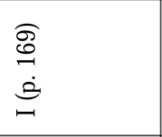 & $\Xi$ & & & & \\
\hline 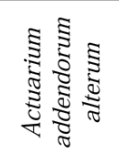 & & 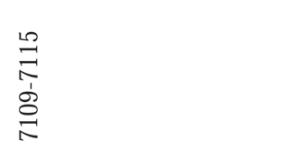 & & & & \\
\hline 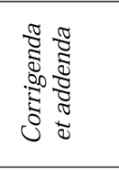 & 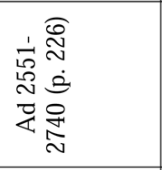 & 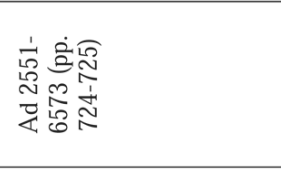 & & & & \\
\hline 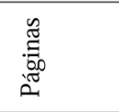 & 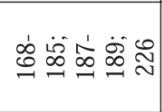 & 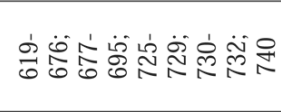 & 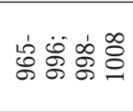 & 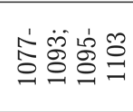 & 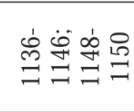 & \\
\hline 兽 & 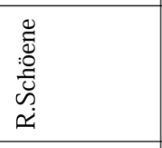 & $\sum_{i}^{\bar{\pi}}$ & 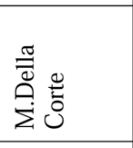 & 离 & 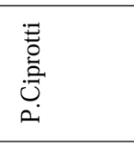 & \\
\hline 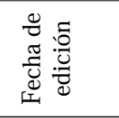 & $\underset{\infty}{\overparen{\infty}}$ & 产 & $\stackrel{\mathscr{\Xi}}{\circ}$ & $\stackrel{2}{9}$ & $\stackrel{8}{\circ}$ & \\
\hline 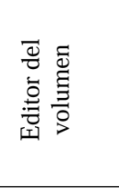 & 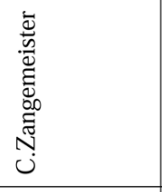 & 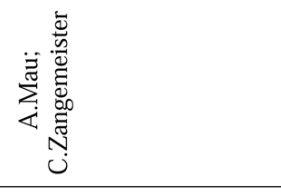 & 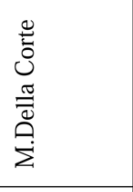 & 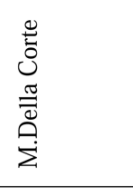 & 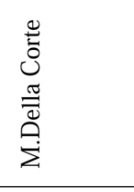 & \\
\hline 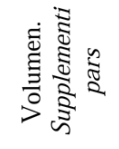 & $\geq$ & $\stackrel{\varkappa}{\gtrless}$ & $\stackrel{m}{z}$ & $\stackrel{m}{\geq}$ & $\stackrel{m}{z}$ & 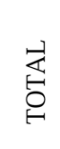 \\
\hline
\end{tabular}


1. CIL, IV, 2638. 2639. 2640; CIL, IV, 6392-6395: mismo titulus o similar sobre distintos objetos.

2. CIL, IV, 2641. 2642: distintos tituli sobre un mismo objeto.

3. CIL, IV, 2645. 2646: titulus y grafito sobre un mismo objeto.

4. CIL, IV, 5986: mismo titulus sobre distintos objetos.

5. CIL, IV, 6304: lectura corregida del titulus CIL, IV, 2852.

La distribución de los 2576 objetos resultantes del vaciado del CIL IV muestra la aportación de cada autor al conjunto de la obra (Fig. 4). Destaca inmediatamente el peso de la labor de A. Mau (49\%). También debe tenerse en cuenta que la dirección de M. Della Corte abarca el 40\%, comprendiendo las obras de F. Weber y P. Ciprotti. Por su parte, la producción de este último autor refleja casi en exclusiva la proporción de objetos con tituli procedente de Herculano (8\%), con la excepción de 4 de ellos que fueron recogidos por A. Mau.

La distribución interna de cada conjunto de los Tituli vasis fictilibus inscripti se hace mediante los aquí denominados "apartados temáticos" (Fig. 5). Su composición viene definida en los textos introductorios de R. Schoene (pp. 171-173) y A. Mau (p. 621), adquiriendo en los conjuntos dirigidos por M. Della Corte un encabezado ya estandarizado. El criterio que siguen estos apartados radica en el valor dado a un aspecto de cada titulus en cuestión. Este valor se halla en uno o varios términos que determinan la posición del titulus en una sucesión ordenada dentro de cada apartado. Esta sucesión puede ser alfabética o numérica. Se hallan sucesiones alfabéticas en los contenidos (apartado II), en los nombres personales (III, VI) y en las letras o grupos de letras de significado incierto (IV, VI). El listado numérico se utiliza en las dataciones consulares (I), cuyo año del calendario gregoriano aparece anotado en aquellos casos en los que se ha podido determinar. También se recurre a este tipo de secuenciación cuando aparecen cifras latinas, recogidas en este caso entre las letras de significación incierta (IV).

Esta última consideración habría afectado seriamente a la ordenación de los tituli griegos, pues muchos de ellos podrían haberse interpretado como cifras. Los autores no se prestaron a distinguir o interpretar los tituli griegos en este sentido, por lo cual su ordenación es exclusivamente alfabética. Siempre que su escritura se ejecutara de derecha a izquierda, de forma descendente, la ordenación alfabética coincidiría con la numérica. Si bien aparecerán mezclados con los términos nominales, guardarán cierta secuenciación numérica. Es decir, las cifras griegas pueden expresarse de distinta forma. En una de ellas el alfabeto griego se divide en letras que expresan unidades, decenas y centenas. Si las cifras se componen de esta forma dan lugar a

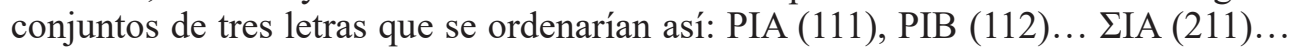
$\Sigma \mathrm{KA}(221) \ldots{ }^{28}$

Por lo demás, los apartados temáticos se rigen por una ordenación cuya base conceptual va desde el tipo de información transmitida (fechas, contenidos, nombres y otros) hasta la técnica de inscripción (grafitos) y la lengua empleada (griego). Sin embargo se podrían establecer lecturas transversales que afectasen a inscripciones

28 CoRtés Copete (ED.) 1999, 48-50. 


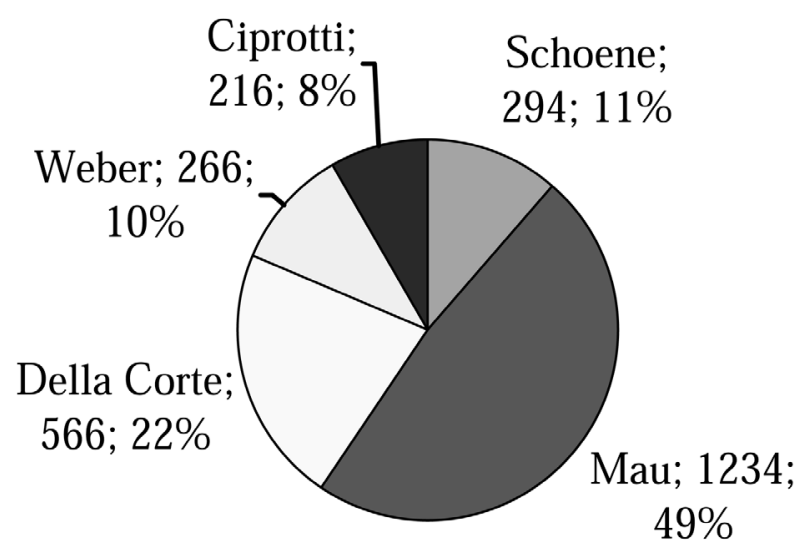

Figura 4. Distribución de 2576 objetos con tituli picti según su catalogación por los autores del CIL IV.

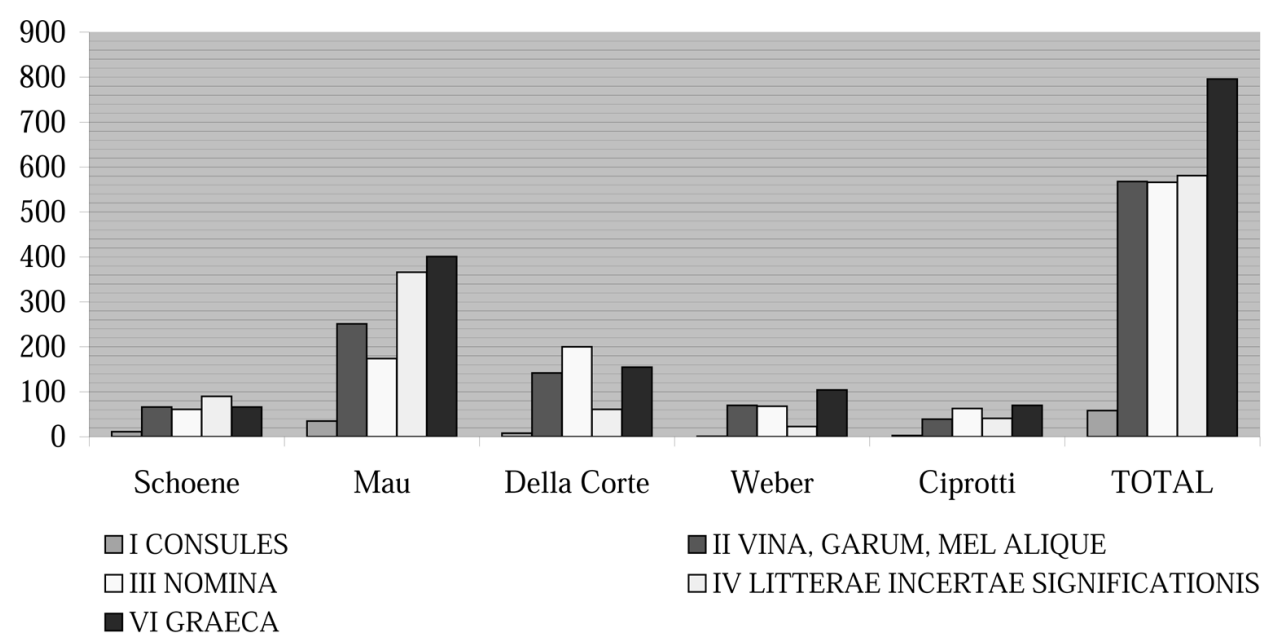

Figura 5. Distribución de 2569 objetos con tituli picti según su clasificación temática y catalogación por los autores del CIL IV.

de los diversos apartados. Esto se hace efectivo, por ejemplo, al considerar términos que por su carácter secundario, según la ordenación del $C I L$, aparecen en un apartado diferente al que les hubiera pertenecido de estar aislados. Tales casos se encuentran frecuentemente en las cifras que acompañan a los tituli que describen el producto envasado. Otro tipo de consideración al respecto es la que replantearía la lectura de ciertas letras, interpretadas como abreviaturas del producto envasado cuando podrían ser tria nomina. 
El peso relativo de cada apartado temático se puede comparar en el trabajo de cada autor, entre las aportaciones de los diferentes autores y en el conjunto del $C I L$ IV. Las relaciones descritas se pueden observar en el gráfico comparativo que se expone a tal fin (Fig. 5). Su creación ha supuesto algunas salvedades que se explican a continuación. Los registros CIL IV 7109-7115 no fueron divididos en apartados temáticos por A. Mau, por tanto han sido excluidos del cómputo, limitado ahora a 2569 objetos. El apartado temático V corresponde a los grafitos, por ello queda fuera de la secuencia establecida. También se ha modificado la división por apartados hecha por R. Schoene. Su trabajo consta de siete apartados, en vez de los seis que disponen los demás autores. De tal forma el apartado V de R. Schoene se suma en el gráfico comparativo al IV. Es decir, los objetos de sus apartados IV y V se incorporan al conjunto de las litterae incertae significationis. Al corregirse la secuencia numeral siguiente, el apartado Graeca de R. Schoene pasaría a ser VI, en vez de VII, coincidiendo de tal forma con la ordenación de los restantes autores.

La representación del número de objetos por apartado temático puede incitar a ciertas reflexiones históricas e historiográficas. Las dataciones consulares aparecen siempre en número muy inferior a las restantes. Los tituli griegos aparecen representados en números significativos en las obras de todos los autores. Su volumen total supera en más de 200 ejemplares al de cualquier otro apartado del cómputo de objetos. Los productos (II), nomina (III) y términos inciertos (IV) alcanzan un volumen muy similar en la suma total. No obstante su relación proporcional es diferente dentro de la obra de cada autor. En las recopilaciones de R. Schoene y P. Ciprotti están bastante igualados en número de objetos, en las restantes las proporciones muestran mayores divergencias. Además, en las obras de R. Schoene y A. Mau los objetos del apartado IV superan a los agrupados en los apartados II y III por separado. Esta tendencia se minimiza o invierte en las obras de M. Della Corte, F. Weber y P. Ciprotti. Ante tal diferencia se puede sugerir que en las recopilaciones dirigidas por M. Della Corte la determinación de las lecturas fue mayor, a favor de significados concretos. Este hecho puede responder a una experiencia acumulada en la interpretación de los tituli, que permitiera identificar con mayor precisión las letras y sus significados. A esta consideración se puede oponer o sumar otra que tenga en cuenta una mejor conservación de las inscripciones recopiladas bajo la dirección de M. Della Corte.

\section{Cuantificación de los objetos epigráficos según la tipología del CIL IV}

E1 CIL IV contiene tres tablas tipológicas Vasorum formae. La primera de ellas fue publicada por R. Schoene en 1871 (tabla I), con anterioridad a las tablas creadas por H. Dressel en $1879^{29}$ y 1899 (CIL XV), habiendo trascendido la nomenclatura de esta última hasta la actualidad. A. Mau añadió las otras dos tablas (II y III) a las que se hace referencia. La tabla I destaca por el realismo de las formas representadas, lo que permite asociar ciertos prototipos a formas bien definidas actualmente. Las representaciones de las tablas II y III son esquemáticas, por lo que las inferencias son más arriesgadas. ${ }^{30}$ De hecho M. Della Corte, F. Weber y P. Ciprotti hicieron poco uso de esta tipología.

Dressel 1879 , tav. VII-VIII.

30 Panella 1976, 151-152. 


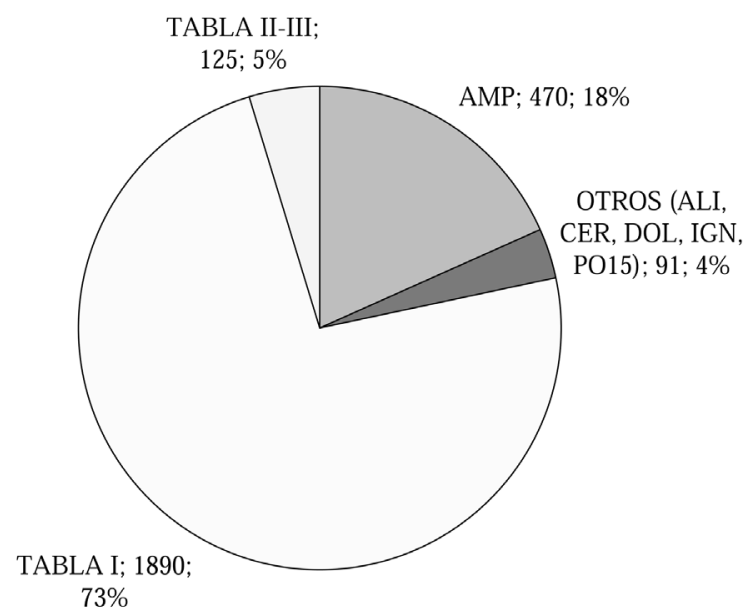

Figura 6. Distribución de 2576 objetos con tituli picti según su adscripción formal, con referencia a las tablas tipológicas Vasorum formae del CIL IV.

Algunas formas (PO01, PO03, PO06, PO17, PO18 y PO19, quizás también PO03, PO15b y PO16) podrían no considerarse ánforas por su tamaño y composición formal. Estos envases destinados al transporte acuático de mercancías, normalmente alimentos, tendrían "dos asas" por definición etimológica y su nombre latino también haría referencia a una medida de capacidad. El amphora equivalía a 2 urnae o 48 sextarii, es decir, $26,11 \mathrm{dm}^{3}$. Estas particularidades formales se han superado mediante el empleo de las denominaciones PO..., al igual que para el resto de objetos. Así se evitan los problemas de adecuación a otras tipologías actuales. Por su parte, el sistema de vaciado CEIPAC prevé la aparición de imprecisiones, tales como la clasificación genérica de un objeto como amphora (AMP). Otros casos que cubren tal diversidad serán alia (formas diversas cuya tipificación inusual no se ha recogido para el sistema de vaciado; ALI), cerámica común (CER), dolium (DOL) e ignotus (cuando no se mencionan datos sobre la forma; IGN). Esta clasificación establecida por el CEIPAC se ha empleado regularmente en el caso AMP. Los demás tipos genéricos se han utilizado eventualmente, como se puede observar en el gráfico de distribución de los objetos por tablas tipológicas (Fig. 6). Se añade a este último grupo la forma PO15, pues este número aparece duplicado en las tablas I y II. Sólo el ejemplar recogido por R. Schoene pertenece sin duda al tipo carrot amphora (PO15a), representado en la tabla I. En cualquier caso, el número de las PO15 es muy reducido, limitándose a 8 ejemplares, como puede verse en el gráfico correspondiente (Fig. 7).

Resulta evidente el empleo preponderante de los 15 tipos de la tabla I (PO01PO15a) frente a los 30 tipos de las tablas II (PO15b-PO30) y III (PO31-PO44). Esta representatividad de los tipos de la tabla I y de la categoría genérica AMP requiere el empleo de gráficos distintos para los cómputos de objetos así clasificados. La diferencia en el número de objetos representados por tipo y autor se observa en el "eje x" de ambos gráficos (Fig. 8; Fig. 9).

Se deben señalar algunas particularidades en la configuración de estos gráficos. La primera de ellas es la integración de formas dudosas. En un total de 32 ocasiones, 


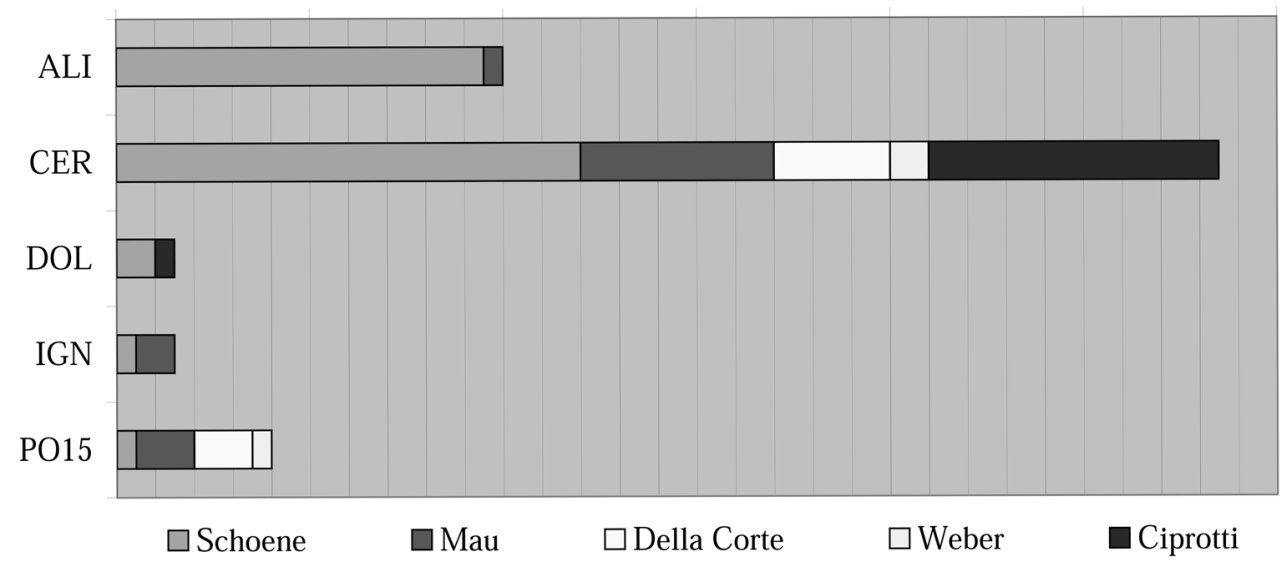

Figura 7. Distribución de 91 objetos con tituli picti de adscripción tipológica imprecisa, según su catalogación por los autores del CIL IV.

la clasificación formal de los objetos se acompañó de un interrogante. A. Mau lo hizo en una sola ocasión, mientras que M. Della Corte es responsable de las restantes. El porcentaje representado por tales casos es muy bajo, por lo que se decidió no excluirlos del cómputo, quedando integrados según su encuadre tipológico correspondiente. Por otro lado, se han representado aquellos casos en los que se emplearon dos tipos distintos para la clasificación de un mismo objeto. Estos tipos duplicados muestran el reconocimiento de singularidades formales que evidenciaban ya entonces la existencia de producciones diferenciadas, pero que no se registraron de manera individualizada en las tablas Vasorum formae. Se incluyen estos tipos duplicados en el gráfico correspondiente, respetando la ordenación numérica general. Las PO08-PO10 son sólo 5 ejemplares (por M. Della Corte), sólo existe un caso de PO08-PO12 (A. Mau) y las PO08-PO13 son 9 (M. Della Corte). El precedente de este modelo duplicado de clasificación lo constituyen los 28 ejemplares de PO12-PO13 definidos por R. Schoene, utilizado en una sola ocasión por A. Mau. Su bajo número hace que apenas sean visibles en el gráfico, pues su escala está dispuesta para representar cifras que puedan alcanzar hasta los 600 objetos. Sin embargo se han mantenido en tal marco para respetar una ordenación numérica simple de los tipos. Algo similar ocurre con las formas PO02, con 3 casos, y las PO03, con 5 ejemplares.

En 62 ocasiones las entradas del CIL IV retoman un registro anterior para hacer visible en la ordenación alfabética algún término en particular o añadir algún dato o lectura alternativa. Una revisión pormenorizada de estos casos puede ilustrar las divergencias metodológicas e interpretativas entre los autores del CIL IV. No obstante, su número apenas supera el 2,4\% del total objetos. La valoración de esta información puede someterse a criterios muy diferentes, pues la impresión de un autor posterior a otro no asegura la mayor fiabilidad de los datos. Por tanto, este ejercicio de discriminación se ha desestimado por el momento. Un ejemplo del tipo de incidencias que esta disposición de la información puede generar se halla en los registros CIL IV 2652 y 5869. Tales entradas se encuentran entre los nomina recogidos por R. Schoene y A. Mau respectivamente. El primer autor indicó que el objeto 


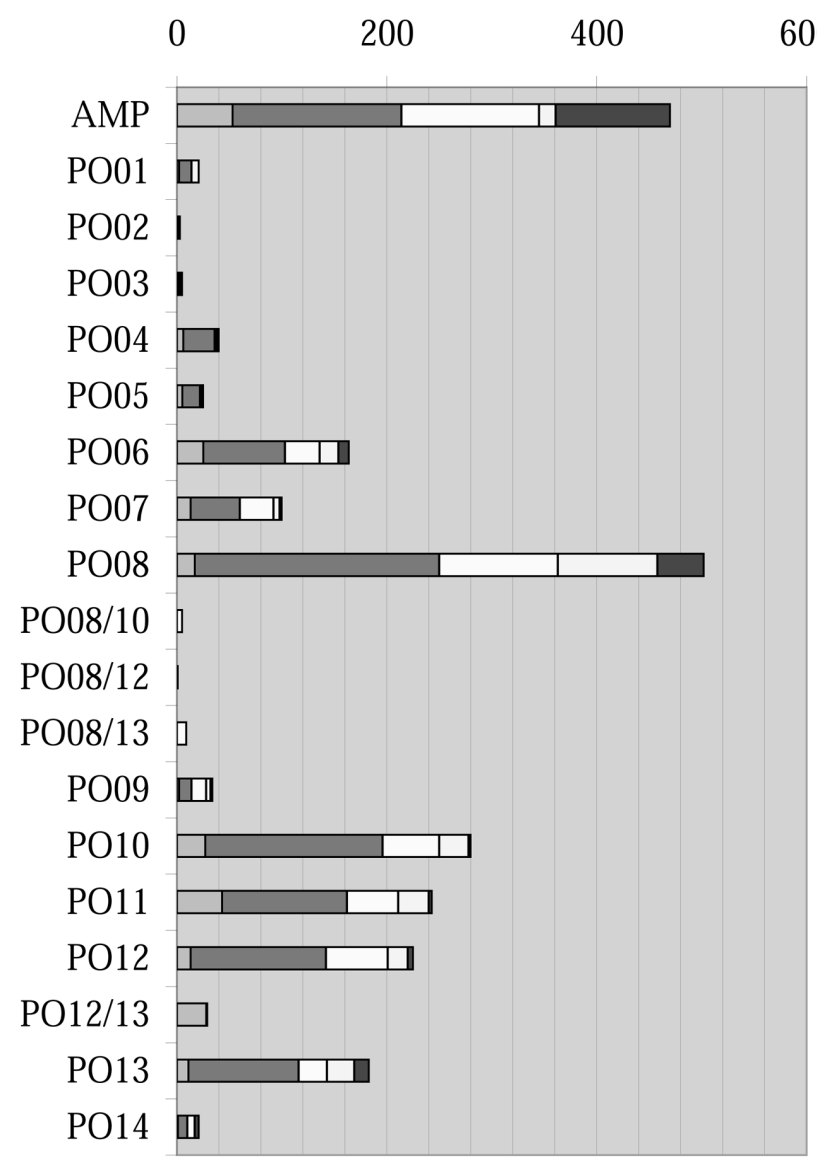

$\square$ Schoene $\square$ Mau $\square$ Della Corte $\square$ Weber $\square$ Ciprotti

Figura 8. Distribución de 2360 objetos con tituli picti adscritos al tipo genérico amphora (AMP; 470 objetos) y a la tabla Vasorum formae I (excepto PO15; 1890 objetos), según su catalogación por los autores del CIL IV.

es una "porzione della pancia di un'anfora". El segundo especificó que la inscripción se halla "in fragmento amphorae (XXIX), eius generis quod frequens est Romae ad montem Testaceum". Este comentario hace alusión a la forma Dressel 20. H. Dressel había completado en 1899 la lectura del fragmento anfórico, depositado entonces en el Museo de Nápoles, incluyéndola con la entrada CIL XV 3664 entre las ánforas del Monte Testaccio. De tal autoridad se desprende la probable corrección de esta asignación tipológica en concreto. Sin embargo, la representación del prototipo de la PO29 ofrece dudas, pudiendo haberse incluido ejemplares de Dressel 24 en este grupo. ${ }^{31}$ Además, las inscripciones documentadas sobre Dressel 20 son asignadas en el CIL IV tanto a las formas PO10 como PO29. ${ }^{32}$ Este hecho desaconseja equiparar de manera automática las formas identificadas mediante las tablas Vasorum formae 


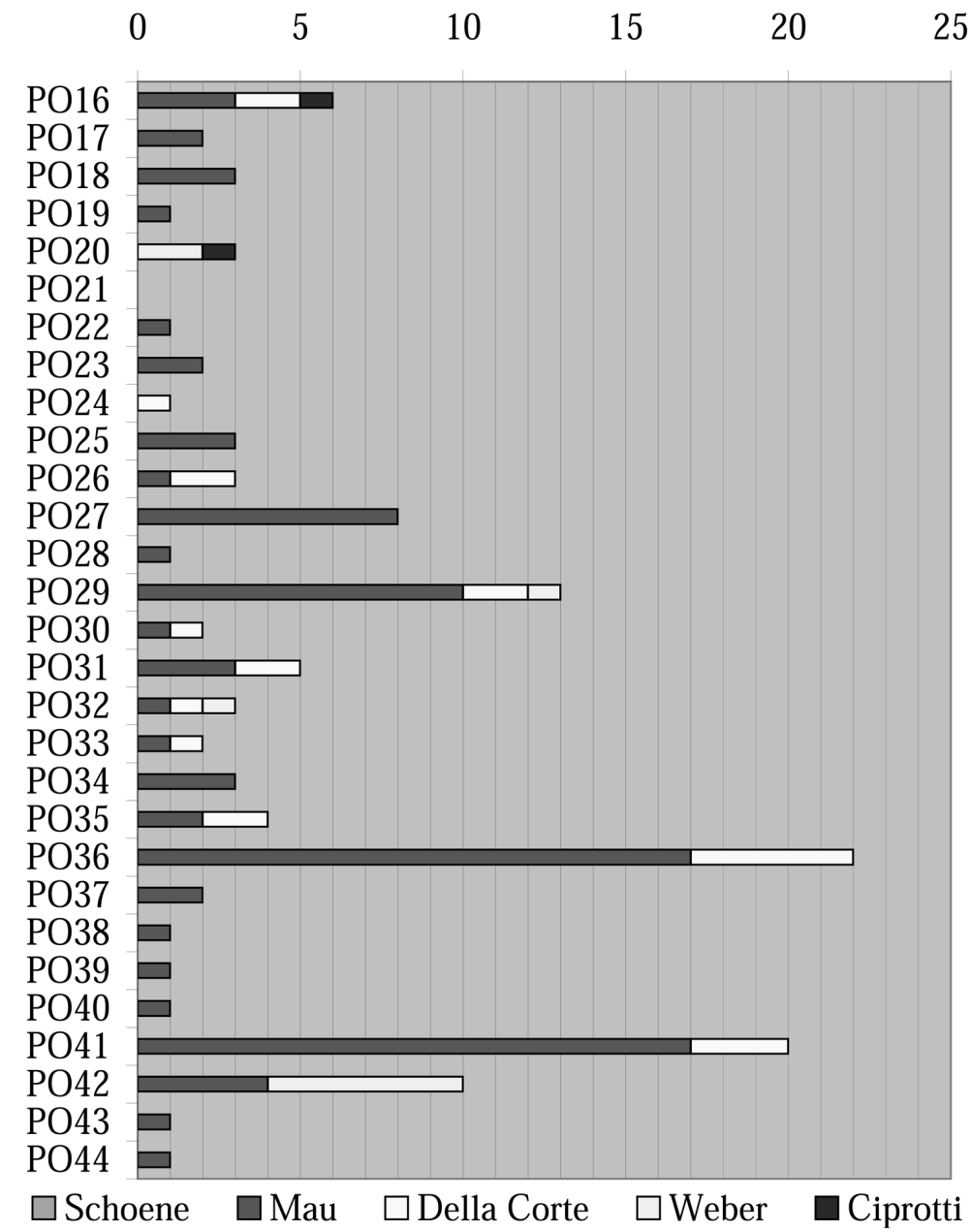

Figura 9. Distribución de 125 objetos con tituli picti adscritos tipológicamente a las tablas Vasorum formae II (excepto PO 15; 49 objetos) y III (76 objetos), según su catalogación por los autores del CIL IV.

con otros tipos de elencos alternativos. La autoría de la publicación del objeto se debe vincular en este caso a la primera entrada que hace alusión a dicho ejemplar. Así, si se hubiera asignado la forma PO29 al registro CIL IV 2652 que se ha comentado, se habría incurrido en una contradicción. En efecto, la forma PO29 no aparece hasta la edición de A. Mau y por tanto fue imposible su uso por R. Schoene. Este autor no aparece representado por ningún objeto del gráfico que recoge los tipos PO16 a PO44, pertenecientes a las tablas II y III, posteriores a su obra. Otro dato aparentemente contradictorio es que no se indiquen objetos de los tipos PO20, PO21 o PO24 para la obra de A. Mau, que presenta las tablas II y III por primera vez. Esto se explica por la exclusión de los grafitos del gráfico aquí representado. Este hecho no resulta extraño si se tiene en cuenta que muchos tipos aparecen representados por un número muy limitado de objetos, al menos para los tituli picti. 


\section{Conclusiones}

El vaciado de los tituli picti del CIL IV para la base de datos CEIPAC dará acceso a un considerable volumen de datos epigráficos estructurados e informatizados. Estos datos cuentan con la ventaja de estar vinculados al entorno de Pompeya, por lo que podrán ser analizados en su conjunto como caso de estudio privilegiado. En efecto, el área en torno al Vesubio constituye uno de los contextos histórico-arqueológicos mejor definidos y más completos que se conocen para el mundo romano. La delimitación de la problemática establecida en torno a la interpretación de los tituli picti y su relación con el comercio romano podrá verse así favorecida. La inclusión de un alto porcentaje de inscripciones sobre recipientes no olearios ayudará a una mejor comprensión de esta parte del ámbito epigráfico. En efecto, se espera prestar apoyo a una investigación afectada por la naturaleza de la información disponible, menos voluminosa y más diversa cuando se trata de alimentos como el vino y las salsas de pescado. Este artículo y los que le sucedan inmediatamente darán cuenta de ciertas limitaciones y potenciales de una información que será más fácilmente analizable con la tecnología actual.

El cómputo de objetos ha mejorado la valoración de los contenidos epigráficos del CIL IV por encima de la simple relación de entradas al catálogo. Los 2576 objetos constatados han servido para sopesar las aportaciones de los diversos autores del CIL IV, quedando en este trabajo reflejada la secuencia en que los tituli picti aparecen en dicha obra. También la compartimentación temática se ha plasmado en su correspondiente gráfico, al igual que los usos de la tipología dispuesta en las tres tablas Vasorum formae. En síntesis, se observa que la obra de R. Schoene tiene cierto valor como precedente formal en la estructuración temática, pero sobre todo por el empleo mayoritario de su tipología en el conjunto del CIL IV. Las tablas II y III de A. Mau fueron usadas en una proporción mucho menor, aun dentro de su propia obra. El volumen de objetos que aporta este autor (49\%) es similar al generado por el trabajo colectivo dirigido por M. Della Corte (40\%). Entre todos ellos incrementaron considerablemente el volumen de datos y, como mostraría la progresiva reducción proporcional de las litterae incertae significationis, sentaron las bases de una mejor comprensión de la epigrafía anfórica.

\section{Referencias bibliográficas}

Aguilera Martín, A. (2004): "Sistematización de los tituli picti anfóricos para la base de datos CEIPAC", [en] J. Remesal Rodríguez (ed.), Epigrafía anfórica. Workshop. Barcelona, 9-10 mayo 2003 (=Instrumenta 17), Barcelona, 105-126.

AndreAu, J. (1974): Les Affaires de Monsieur Iucundus (=Collection de l'École Française de Rome 19), Roma.

AquiluÉ, A. (2014): "Algunos comentarios sobre las bases de datos de las cerámicas de la antigüedad clásica en la Península Ibérica", Boletín de la Sociedad de Estudios de la cerámica antigua en Hispania. Ex Officina Hispana 5, 42-48. 
Ayllón Martín, R. - Pérez González, J. (2013): “La base de datos online del CEIPAC. Una herramienta para el estudio de la economía antigua: el caso del muro de Adriano", Ar@cne. Revista electrónica de recursos en Internet sobre Geografía y Ciencias Sociales 171.

Bernal, D. - Cottica, D. - García-Vargas, E. - Toniolo, L. - Rodríguez-Santana, C. G. - Acqua, C. - Marlasca, R. - SÁez, A. M. - Vargas, J. M. - Scremin, F. LANDI, S. (2014): "Un contexto excepcional en Pompeya: la pila de ánforas de la Bottega del Garum (I, 12, 8). Avance de un estudio interdisciplinar", Rei Cretariae Romanae Fautorum Acta 43, 219-232.

Cappelletto, E. - Bernal Casasola, D. - Cottica, D. - Bustamante Álvarez, M. - Lara Medina, M. - SÁez Romero, A. M. (2013): “Urcei per salse di pesce da Pompei-Ercolano: una prima analisi”, [en] D. Bernal - L. C. Juan - M. Bustamante - J. J. Díaz - A. M. Sáez (eds.), Hornos, talleres y focos de producción alfarera en Hispania (=Monografías ex officina hispana I/II), Cádiz, 271-280.

Cormack, I. G. - Loza-Álvarez, P. - Sarrado, L. - Tomás, S. - Amat-Roldan, I. - Torner, L. - Artigas, D. - Guitart, J. - Pera, J. - Ros, J. (2007): "Lost writing uncovered by laser two-photon flourescence provides a terminus post quem for Roman colonization of Hispania Citerior", Journal of Archaeological Science 34, 1594-1600 (https://doi. org/10.1016/j.jas.2006.11.016).

Cortés Copete, J. M. (ED.), (1999): Epigrafía griega, Madrid.

De Sena, E. C. - IKÄHeImo, J. P. (2003): “The supply of amphora-borne commodities and domestic pottery in Pompeii 150 BC-AD 79: preliminary evidence from the House of the Vestals", European Journal of Archaeology 6/3, 299-319 (http://dx.doi.org/10.1177/146 195710300600305).

Dressel, H. (1879): "Di un grande deposito di anfore rinvenuto nel nuovo quartiere del Castro Pretorio", Bulletino della Commissione Archeologica Comunale di Roma, Serie II 7/1, 36-64.

Elliott, T. (2015): "Epigraphy and digital resources", [en] Ch. Bruun - J. Edmonson (eds.), The Oxford Handbook of Roman Epigraphy, New York, 78-85.

Giordano, C. - CASAlE, A. (1991): "Iscrizioni pompeiane inedite scoperte tra gli anni 19541978”, Atti della Accademia pontaniana XXXIX, 273-378.

LAGÓSTENA BARrios, L. (2002-2003): “La aportación al conocimiento de la sociedad de la costa Ulterior en época republicana y julio-claudia. El registro $\delta$ en los tituli picti de las ánforas salsarias de Castra Praetoria", Lucentum XXI-XXII, 227-236 (https://doi. org/10.14198/LVCENTVM2002-2003.21-22.15).

MANACORDA, D.

(1975): "Proposta per una identificazione dell'anfora Dressel 24", Archeologia Classica XXVII/2, 378-383.

(1977): “Anfore spagnole a Pompei", [en] L'instrumentum domesticum di Ercolano e Pompei nella prima età imperiale (=Quaderni di Cultura Materiale 1), Roma, 121-133.

Marangou-Lerat, A. (1995): Le vin et les amphores de Crète. De l'époque classique à l'époque impériale (=Études Crétoises 30), Paris.

Martínez MaGanto, J. (2000): “Inscripciones sobre ánforas de salazón: interpretación sobre la estructura y significación comercial de los tituli picti”, [en] Congreso Internacional Ex Baeticae Amphorae. Conservas, aceite y vino de la Bética en el Imperio Romano. Sevilla - Écija, 17 al 20 de diciembre de 1998, Écija, 1207-1219.

PANELla, C.

(1976): "Per uno studio delle anfore di Pompei. Le forme VIII e X della tipologia di R. Schoene", Studi Miscellanei 22, 149-166.

(1977): “Anfore tripolitane a Pompei”, [en] L'instrumentum domesticum di Ercolano e 
Pompei nella prima età imperiale (=Quaderni di cultura materiale 1), Roma, 135-149.

Panella, C. - Fano, M. (1977): "Le anfore con anse bifide conservate a Pompei: contributo ad una loro classificazione", [en] Méthodes classiques et méthodes formelles dans l'étude typologique des amphores. Actes du colloque de Rome, 27-29 mai 1974 (=Publications de l'École française de Rome 32), Roma, 133-177.

PEÑA, J. T.

(2007a): Roman Pottery in the Archaeological Record, New York (https://doi.org/10.1017/ CBO9780511499685).

(2007b): "Two groups of tituli picti from Pompeii and environs: Sicilian wine, not flour and hand-picked olives", Journal of Roman Archaeology 20, 233-254 (https://doi. org/10.1017/S1047759400005390).

Peña, J. T. - McCallum, M.

(2009a): "The Production and Distribution of Pottery at Pompeii: A Review of the Evidence; Part 1, Production”, American Journal of Archaeology 113/1, 57-79 (http:// dx.doi.org/10.3764/aja.113.1.57).

(2009b): "The Production and Distribution of Pottery at Pompeii: A Review of the Evidence; Part 2, the Material Basis for Production and Distribution", American Journal of Archaeology 113/2, 165-201 (http://dx.doi.org/10.3764/aja.113.2.165).

Pérez GonzÁlez, J. (2014): "La base de datos on line del Ceipac. Los tituli picti”. Ar@cne. Revista electrónica de recursos en Internet sobre Geografía y Ciencias Sociales 190, Barcelona.

REMESAL RoDrígueZ, J.

(2007): "Epigrafía anfórica. La base de datos CEIPAC", [en] Acta XII Congressus Internationalis Epigraphiae Graecae et Latinae (Barcelona, 3-8 Septembris 2002) (=Monografies de la Secció Històrico-Arqueològica X), Barcelona, 1179-1182.

(2008): "El grupo CEIPAC y los estudios de epigrafía anfórica en España", [en] D. Bernal - A. Ribera Lacomba (eds.), Cerámicas hispanorromanas. Un estado de la cuestión. Actas del XXVI Congreso Internacional de la Asociación Rei Cretariae Romanae Fautores, Cádiz, 807-808.

(2012): “Corpus versus Catalog, propuestas sobre una vieja cuestión”, [en] M. E. Fuchs R. Sylvestre - C. S. Heidenreich (dirs.), Inscriptions mineures: nouveautes et reflexions. Actes du premier colloque Ductus (19-20 juin 2008, Université de Lausanne), BernBerlin-Bruxelles-Frankfurt am Main-New York-Oxford-Wien, 83-93.

(2013): "Corpus international d'épigraphie amphorique", [en] Bientôt un siècle de soutien à des réalisations intellectualles majeures. Towards a century of support to major intellectual archievements, Cracovie-Bruxelles, 55-58.

Remesal Rodríguez, J. - Díaz-Guilera, A. - Rondelli, B. - Rubio, X. - Aguilera, A. Martín-Arroyo, D. - Mosca, A. - Rull, G. (2014): "The EPNet Project. Production and distribution of food during the Roman Empire: Economic and Political Dynamics", [en] S. Orlandi - S. Santucci - V. Casarosa - P. M. Liuzzo (eds.), Information Technologies for Epigraphy and Cultural Heritage. Proceedings of the First EAGLE International Conference. Europeana Eagle Project, Roma, 455-464 (http://dx.doi.org/10.13133/97888- 98533-42-8).

Remesal Rodríguez, J. - Aguilera, A. - García Sánchez, M. - Martín-Arroyo, D. - Pérez González, J. - Revilla Calvo, V. (2015): “Centro para el Estudio de la Interdependencia Provincial en la Antigüedad Clásica (CEIPAC)", Pyrenae $\mathrm{N}^{\circ}$ Especial 50è Aniversari, 245-275 (http://dx.doi.org/10.1344/Pyrenae2015.SpecialNumber.1.6). 